\section{Requiem for a supercollider}

\author{
A Hole in Texas \\ by Herman Wouk \\ Little, Brown: 2004. 278 pp. \$25, Can\$37

\section{Geoff Brumfiel}

"Gentlemen, the Chinese have got the Higgs boson."

So begins A Hole in Texas, Herman Wouk's latest novel, which revolves, rather improbably, around the world of high-energy physics. The 88-year-old Pulitzer Prizewinning author of War and Remembrance and The Winds of War is famous for his depictions of wars and the men who fight them, but his twelfth novel concerns exotic particles and the men (and women) who discover them. The result is an amusing and at times arcane yarn that will make a good summer read for scientists - especially those who have had a frustrating time explaining their work to governments or the popular press.

Set in the not-too-distant future, the book has as its protagonist Guy Carpenter, a silvery, fifty-something physicist who once worked on the US Superconducting Super Collider (SSC), which really existed. As Wouk explains in the novel's foreword, the supercollider was a giant US particle accelerator designed to find the Higgs boson, an elusive particle that many physicists believe endows other particles with mass. After spending billions of dollars on the project, Congress withdrew support in 1993, leaving behind a couple of thousand unemployed physicists and a partly dug tunnel in Waxahachie, Texas - the 'hole' of Wouk's title.

Carpenter has moved on since the SSC was shut down, but like any good dime-novel hero, his past comes back to haunt him. When word gets out that the Chinese are about to publish the discovery of the Higgs boson (in Nature, of course), Carpenter is asked to explain the significance of the find to a movie-star-turned-Congresswoman. By the time he arrives in Washington, the media are swarming around the story, and a secret memo is circulating on Capitol Hill that the Chinese are building a 'boson bomb'. Word of the bomb gets out to the press and Carpenter is rapidly drawn into the ensuing national panic. He is pursued by a "pestiferous ferret" of a reporter, who is determined to find out more about Carpenter's graduate-school liaison with the female physicist now leading the Chinese programme. He is wined and dined by Hollywood bigwigs, who want to make a movie about the boson bomb. And he is called to testify by an unscrupulous Congressman who voted to kill the supercollider years ago and is now seeking a scapegoat on whom he can lay the blame.

If all this sounds a little absurd, that's the

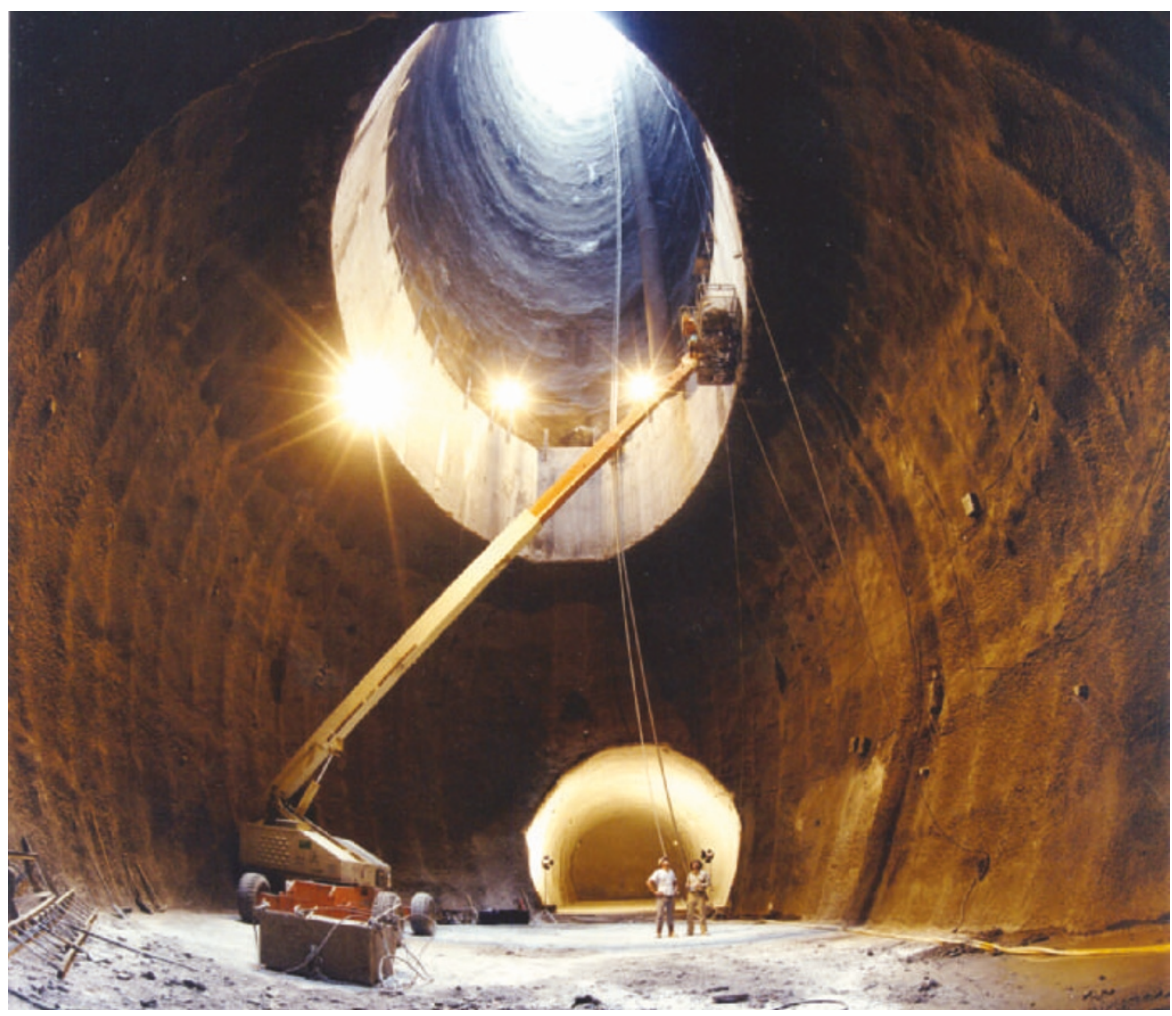

Billion-dollar hole: Congress pulled the plug on the real Superconducting Super Collider in 1993.

whole point. Wouk's work is satire, and it delivers its fair share of laughs (the movie about the boson bomb is set to star Julia Roberts as "the astronaut"). At its heart is an idea summed up nicely by one of the book's physicists: "Science today needs huge funding, and we're funded by a scientifically illiterate society."

That message would be fine if it were not for the breathtaking arrogance of the book's physicist characters who deliver it. They go to great lengths to trumpet the ignorance of the media, Congress and the public, and one even goes so far as to say that the gap between someone who knows quantum mechanics and someone who does not is as wide as that between man and monkey. This too could be satire, but reading page after page of the stuff you get the uneasy feeling that Wouk might actually mean it. By the way, I got an A minus in quantum mechanics.

This is far from being the book's only flaw. The scientific explanations are pat and usually come in the form of long e-mails that bog down the plot. A trip to the hole in Waxahachie takes far longer than it should and reads like a giant I-told-you-so. The women of the novel, whether they be hard-nosed members of Congress or top-notch physicists, fall helplessly into Carpenter's powerful arms. And everybody's discussion of the Chinese people can, at times, verge on racism ("They're touchingly sentimental, the Chinese, once you're past those forbidding Asian features and the different eyes," Carpenter declares).

The book's ending also falls flat. Without spoiling too much, I'll say that the furore over the Chinese discovery forces the public to focus on the importance of science. In the modern world that seems unlikely. After all, the Chinese launched their first man into space last autumn at a time when the US shuttle programme was out of commission, but no alarm bells sounded. The threat posed by low-tech extremists seems far scarier than the rise of Chinese science. It was that fact, along with the rather wistful view of the SSC, that left me feeling that A Hole in Texas is something of an anachronism. Still, it will make good beach reading for researchers who want a scientific thriller and a bit of a chuckle.

Geoff Brumfiel is Nature's Washington-based physical sciences correspondent.

\section{Bright blue dot}

\section{The Privileged Planet: How Our Place in the Cosmos is Designed for Discovery \\ Guillermo Gonzalez \& Jay W. Richards} Regnery: 2004. 464 pp. \$27.95

\section{Douglas A. Vakoch}

"Our planet is a lonely speck in the great enveloping cosmic dark," wrote astronomer Carl Sagan in Pale Blue Dot (Random House, 1994). Reflecting on the image of Earth sent back from the Voyager 1 spacecraft in 1990, he suggested that "our posturings, our imagined self-importance, the delusion that we have some privileged position in the Universe, are challenged by this point of pale light."

In The Privileged Planet, astronomer Guillermo Gonzalez and the philosopher and theologian Jay W. Richards present a markedly different view. They argue that our 


\section{Exhibition}

\section{Eyes that follow you around the room}

Since 1979, the industrial city of Linz in Austria has been the unlikely home of Ars Electronica, a centre for the development and dissemination of digital art and media. The centre has evolved to include an annual festival, a 'cyberarts' competition and 'The Futurelab', a media lab where interdisciplinary collaborators design and engineer new installations.

To celebrate Ars Electronica's 25th anniversary, New York City's American Museum of the Moving Image is hosting Digital AvantGarde, a series of exhibitions and screenings of projects that featured prominently in earlier competitions. Linz will have its own anniversary celebration during the first week of September.

The New York series, which runs until 18 July, includes John Gerrard's Portrait Diptych: Nadia (formerly called Networked Portrait), an interactive portrait that can be changed with the touch of a finger on a screen. The installation, shown here, consists of two liquid-crystal-display touchscreens, each presenting the computer-generated image of a particular individual.

By dragging a finger across an eye or the

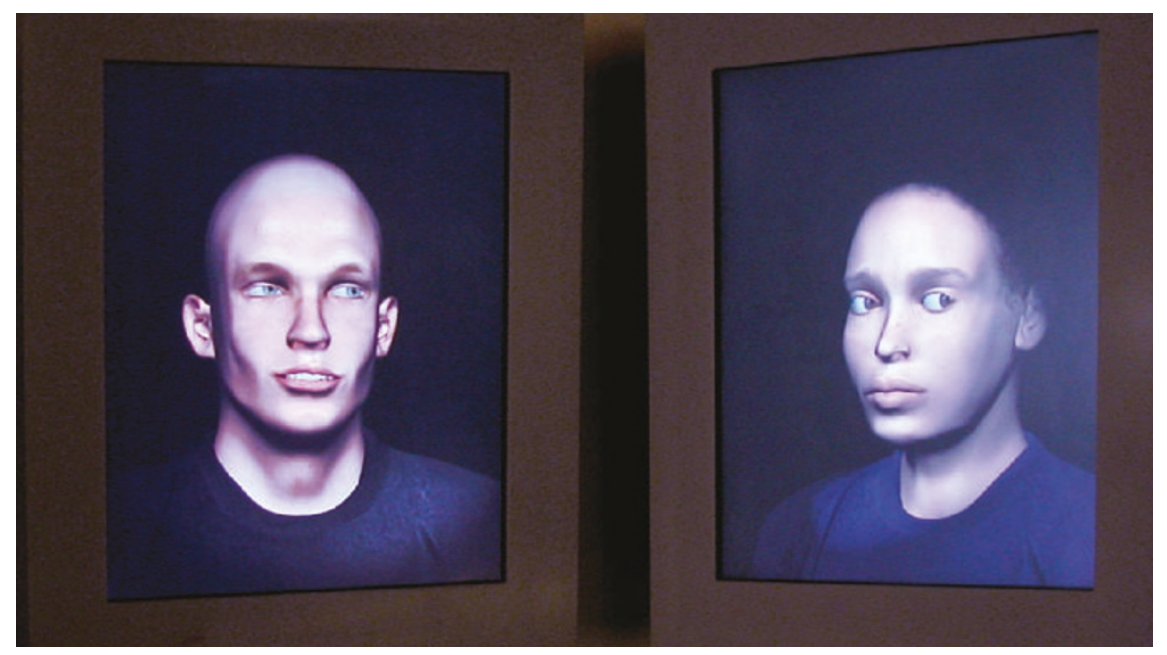

corner of the mouth in one of the images, the viewer can impart some emotion to the otherwise expressionless visage. When the screens are turned toward each other, the other face responds by subtly changing its own expression. The two faces then continue to respond to each other.
The portrait is seen as one of the last bastions of permanence at a time when images can be erased or modified at will. But even the portrait, it seems, can be digitized and updated continually — for example, to reflect one's mood.

Alan Packer planet is significant, perhaps being uniquely situated to foster both complex life and scientific discovery. Gonzalez and Richards believe that intelligence may be a rare phenomenon in our galaxy. They make their case, in part, by drawing on arguments others have given before, such as Peter D. Ward and Donald Brownlee in Rare Earth (Springer, 2000). But they go far beyond estimating the prevalence of extraterrestrial life. As they summarize: "The myriad conditions that make a region habitable are also the ones that make the best overall places for discovering the universe in its smallest and largest expressions. This is the central argument, the central wonder of this book."

Drawing on a framework for inferring design proposed by philosopher and mathematician William Dembski in The Design Inference (Cambridge University Press, 1998), Gonzalez and Richards argue that the correlation between the conditions that make habitability possible and those that make it possible to learn about the Universe is so exquisite and improbable as to suggest intelligent design.

For example, by raising the tides the Moon helps move nutrients from the land to the ocean, fostering life in the intertidal zone. If the Moon were farther from the Earth, the authors argue, it would need to be much larger to have the same effect on the tides; if it were closer, it might well be less spherical, causing other problems. So, Gonzalez and Richards argue, the Moon is located at a distance from Earth that is very conducive to life. It is also at an optimal distance for scientific discovery (or measurability), they contend, as the disk of the Moon provides a perfect eclipse of the Sun. They argue that without such perfect solar eclipses, humans would have been deprived of important information about the Sun's chromosphere.

A single such instance linking habitability and measurability might be dismissed as a coincidence, but Gonzalez and Richards claim that the correlation across many phenomena cannot be explained by chance. By including astronomical and geological phenomena in their search for evidence of purpose in the cosmos, The Privileged Planet expands the discussion of intelligent design far beyond its usual contemporary focus on the complexity of biological systems and the fundamental physical constants.

Ultimately, however, the authors are in a poor position to argue that Earth is optimally located for both habitability and measurability. They try to establish habitability requirements by comparing Earth with other locations in the galaxy. Unfortunately, we lack the data required for a well-reasoned comparison. If we had many examples of planets that do and do not bear life, and an explanation for why the conditions on some planets led to life while those on others did not, we might be able to establish an accurate metric of habitability. Until then, we are forced to extrapolate measures of habitability from a sample of one inhabited planet.

Regrettably, anyjudgements of optimality may be biased by the local conditions and historical contingencies through which our life and our science have evolved, rather than accurately reflecting the range of possible preconditions for habitability and measurability. Potential readers of The Privileged Planet would do well first to familiarize themselves with the biases that can result from this kind of selective sampling. A good primer is Nick Bostrom's Anthropic Bias (Routledge, 2002).

Caution seems especially in order given that the authors have intentionally limited themselves to our knowledge of the Universe gained through selected observational sciences, such as comparative planetary geology, solar physics and astronomy, rather than including more laboratory-based sciences. Similarly, although the authors attempted to avoid cherry picking instances of measurability that support their position by focusing on important observations in these fields, the vagueness of such a criterion makes their selection rather subjective.

So far, Earth is the only planet we know that has the privilege of bearing life that searches for signs of other intelligence whether in the form of other technological beings transmitting evidence of their existence or through patterns indicating underlying design. It may be some time, however, before we can accurately judge whether our blue dot is - as planets go - commonplace, unique or somewhere in between.

Douglas A. Vakoch is at the SETI Institute,

2035 Landings Drive, Mountain View,

California 94043, USA. 